\title{
Entre sociedades y sociologías latinoamericanas Entrevista al profesor Manuel Antonio Garretón
}

El profesor Manuel Antonio Garretón es uno de los sociólogos de mayor relevancia en América Latina en la actualidad. Uno de los principales impulsores del modelo de análisis de la matriz socio-política, se ha formado tanto en Chile como en Francia, y hace ya varios años divide su tiempo de docencia entre la Facultad de Ciencias Sociales de la Universidad de Chile y la Escuela de Política y Gobierno en la Universidad Nacional de San Martín, en Buenos Aires.

Esta pequeña entrevista fue realizada en diciembre de 2010, en el marco de los cursos de posgrado que el profesor Garretón imparte en Buenos Aires.

Pd.: En primer lugar, profesor, quisiéramos que nos relatara su visión, en líneas generales, de los grandes surcos en la trayectoria de la sociología latinoamericana hasta hoy. Los rasgos que la caracterizarían como diferente de la sociología norteamericana o europea.

M. A. G.: Mi impresión es que de algún modo la sociología latinoamericana fue tributaria de la sociología tanto americana en determinado momento como de la sociología europea, si uno piensa en la vertiente marxista, por ejemplo, aunque no es la única. Fue tributaria en su origen, en su nacimiento y en lo que podríamos llamar el modelo fundacional de la sociología.

Cuando se produce la destrucción de las universidades por las dictaduras militares en los años 60 o 70, se empieza - pero también en países en los que no hubo dictaduras militares como en el caso de México, por ejemplo- se empieza a desarrollar un tipo de sociología, algunos de cuyos elementos ya estaban presentes en el período anterior, pero que tiene una relación de mayor tensión o distancia con lo precedente, porque se trata más que de caracterizar una problemática a partir de categorías que habían sido desarrolladas en otra parte, una problemática original, se trata ahora más bien de desarrollar las categorías propias para una problemática nueva que tenía que ver con el tipo de dictaduras. Y entonces la relación es yo diría más original en el sentido de que no se va a los textos o a lo que se está haciendo en otras partes solo para transcribirlo y aplicarlo, sino que - y esta fue un poco la sociología de los grandes 
paradigmas en un largo período - a partir de un determinado problema se interrogan todas las vertientes disponibles sin lo que podríamos llamar la presencia de un dogma que está dado por uno de los paradigmas que hubo, vigentes allá. Entonces se hacen combinaciones mucho más eclécticas para intentar entender no solo las dictaduras, sino las formas de oposición, las nuevas formas de oposición de los individuos y también las salidas de las dictaduras, que fueron fundamentalmente las luchas democráticas.

Una vez instauradas las democracias, la pregunta sociológica fundamental tiene que ver en parte con una pregunta que se hace en todas partes del mundo y que tiene que ver con la finalización de un momento, de una etapa, o de una sociedad moderna actual, de la modernidad y, en el caso de América Latina, esto va acompañado con el hecho de que somos países más globalizados que globalizantes dentro del proceso de globalización.

Entonces uno diría que aparecen tres grandes problemáticas: uno, cómo se resinsertan estos países, y eso lleva a plantearse el tema que ningún país, salvo quizá China e India, se van a insertar solos, y lleva entonces a plantearse el tema con nuevos bríos de la integración latinoamericana que se empieza a acercar a momentos de decisiones mucho más duras, como lo que tiene que ver, por ejemplo, con la política energética, el tema medioambiental, que ningún país puede resolver solo, y que ningún país puede plantearse solo frente al mundo,por lo menos en el caso latinoamericano, como lo ha entendido bien la gente de la comunidad europea. Entonces por un lado está el tema de la globalización, por otro lado está el tema de la modernidad y por otro lado está el tema de la reconstrucción de la relación entre estados. Respecto del tema de la modernidad, digamos, la pregunta es si Latinoamérica es o no o puede llegar a constituir en un mundo globalizado un nuevo modelo de modernidad o un modelo de modernidad distinto, que tiene sus variantes, por supuesto, respecto de los países, y eso es lo que lleva a poner como un tema fundamental — cosa que no había existido en el período anterior - el tema de la cultura. Y por otro lado, y ligado al tema del Estado, está el estallido — si uno quiere - de lo que hemos Ilamado la matriz estatal-nacionalpopular, la matriz clásica, que significa que se replantean los problemas por un lado de aparición de nuevos actores que habían sido avasallados, ocultados en el predominio del modelo industrializador, por supuesto después con las dictaduras militares, pero donde lo que importaba más bien era un Estado que se veía como un actor unificado que no daba cuenta de la diversidades de pueblos y naciones dentro de cada uno de los países; entonces el tema del surgimiento de nuevos actores que redefinen la relación entre Estado y sociedad, esta vez $-\mathrm{y}$ eso es lo nuevo- en el marco democrático. $Y$ entonces la pregunta hoy día es por estos modelos, estas formas de reconstitución de las relaciones entre Estado y sociedad. En ese sentido, hay temas que acercan a la sociología sobre todo yo diría europea a la americana, muchas veces en 
términos de tipos metodológicos, pero a la europea en términos de contenido, que tienen que ver con la redefinición de la ciudadanía y el ciudadano, el descentramiento, la pérdida de centralidad del tema de la política y el surgimiento de actores que no están referidos al tema de la identidad de clases sociales, que no están solamente referidos a eso. Entonces, por ejemplo, toda la discusión sobre el papel de la sociedad civil, que también es un tema muy importante en Europa, pero también el tema de la reconstrucción de los estados. De hecho, el giro hacia la izquierda del cual se ha hablado tanto en el último tiempo revela la búsqueda de un tipo de Estado que supere al Estado Nacional Popular clásico, que dé cuenta de las diversidades, que sea Estado multinacional en algunos casos, pero que también reconstruya las capacidades de un Estado de Bienestar que no sea puramente clientelar. Entonces, esos son los tipos de problemas que llevan a los temas de la sociología hoy.

Pd.: Una de las tensiones de las sociedades a escala global pero que tiene particulares implicancias en Latinoamérica es la exigencia de una mayor equidad, de mayores procesos de la distribución de riqueza y los nuevos imperativos — nuevos me refiero a los últimos 30 o 40 años en todo caso- de la atención debida a nuevos actores, o del cuidado del medio ambiente. ¿Qué elementos serían particularmente importantes para tener en cuenta en el momento de evaluar estos procesos de tensión? ¿Cómo poder acercarnos a ellos desde la sociología teniendo en cuenta las realidades latinoamericanas, estas exigencias de producción, de equidad, y estos nuevos actores?

M. A. G.: Bueno, lo primero es que hoy día con los fenómenos de globalización, pero especialmente con la entrada de China en América Latina, se hace cada vez más evidente - teniendo en cuenta que en los últimos tiempos a habido unas tasas de crecimiento muy altas en América Latina - por un lado el tema del modelo productivo, hasta qué punto las relaciones con China van a significar una reprimerización, digamos, en la medida en que aseguran la compra de productos sin valor agregado, y que a los productos de valor agregado China tiene unas ventajas competitivas enormes prácticamente por su control de la mano de obra. Entonces está, por un lado, el tema del modelo productivo, que no ha sido definido. En segundo lugar, hay ciertos núcleos que yo señalaría por lo menos tres que no tienen solución a nivel nacional, que son, por un lado el tema energético, por otro lado el tema medioambiental y el tercero lo relativo a las políticas científicas. Ninguno de estos tres se puede resolver a nivel nacional. Ni siquiera Brasil puede hacerlo. $\mathrm{Y}$ entonces esto supone -como decía anteriormente - una dificultad en términos de integración, tanto respecto de la matriz energética para América Latina y la capacidad de América Latina de negociar el tema energético con el resto del mundo, como con el tema medioambiental, donde está 
entre otras cosas el tema del Amazonas, pero no solo eso, están los temas que tienen que ver con el calentamiento global y otros. No son resolubles a escala puramente nacional, sino que uno debiera pensar que ahí América Latina debe tener una posición al respecto, lo que implica negociaciones muy complejas y, en tercer lugar, el tema de la política científica, donde enfrentar a aquella dimensión de la sociedad del conocimiento, que no agota todas las dimensiones pero es una de ellas, implica una política científica que ningún país está en capacidad de hacer. La cantidad de doctores que usted necesita en las distintas áreas muy especializadas y muy complejas se tiene que producir unificando recursos. Ya ha habido una iniciativa interesante en ese sentido, al menos en la parte de formación, obviamente de Brasil, y a través de la creación de la Universidad de Integración Latinoamericana, la UNILA, que tiene su sede en Foz de Iguazú. Allí hay un intento de crear una institución latinoamericana que el conjunto de países no ha podido hacer, entonces se hace bajo el liderazgo de Brasil. Y yo digo que al menos ahí hay un avance importante.

Entonces está el tema de la definición de un modelo productivo, sobre todo diría necesario, para evitar una reprimarización frente a la demanda china, tema que no es menor. Está el tema de las decisiones duras respecto de la integración, y yo creo que la tercera gran cuestión tiene que ver con el tema de la igualdad básica que nuestros países no han logrado resolver pese a las tasas de desarrollo y pese a haber avanzado bastante en el tema de superación de la pobreza. No digo que este tema se haya superado, sigue siendo un desafío, pero el tema central de América Latina es el tema de la igualdad en el grupo porque podemos tener en el interior de un país varios países. Y los procesos de globalización y el tipo de Estado que construyamos son fundamentales respecto del tema de la igualdad. Esto ha sido puesto por CEPAL como uno de los temas principales este año. La conferencia de la CEPAL se llama "La hora de la igualdad", y eso implica pensar en un papel redistributivo del Estado. ¿Están los distintos países con la posibilidad de un Estado que tenga la suficiente legitimidad, eficiencia, eficacia, niveles de participación como para poder hacer procesos redistributivos que no se hagan por la coerción, sino que se hagan por la presencia de mayorías políticas, por consenso?, ¿es posible lo que han llamado algunos un nuevo pacto de cohesión social? Ese es el gran tema hoy en día.

Pd.: Suponemos que esta indefinición del modelo productivo en varios países de Latinoamérica tendría cierta implicancia en cuanto a cómo considerar la existencia y los efectos de una reprimarización económica, por ejemplo, y en relación con una de las dimensiones que usted mencionó, que es la medioambiental.

M. A. G.: Sí, pero también tiene consecuencias en el modelo de igualdad. Los modelos básicamente exportadores son modelos desigualitarios. Entonces, obviamente 
De Prácticas y discursos/ Universidad Nacional del Nordeste/ Centro de Estudios Sociales

Año 1, Número 1, 2012

ISSN 2250-6942

son todos problemas que están en conjunto y que se plantean junto a una nueva manera de revisar el tema de la democracia, que consiste hoy en día no en la mera existencia de regímenes democráticos, sino en su relevancia y su calidad. 